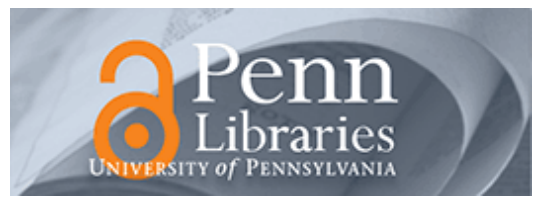

Studies in Visual Communication

Volume 8

Issue 1 Winter 1982

Article 9

1982

\title{
Political Cartoons and American Culture: Significant Symbols of Campaign 1980
}

Michael A. DeSousa

Martin J. Medhurst

Recommended Citation

DeSousa, M. A., \& Medhurst, M. J. (1982). Political Cartoons and American Culture: Significant Symbols of Campaign 1980. 8 (1), 84-97. Retrieved from https://repository.upenn.edu/svc/vol8/iss1/9

This paper is posted at ScholarlyCommons. https://repository.upenn.edu/svc/vol8/iss1/9

For more information, please contact repository@pobox.upenn.edu. 
Political Cartoons and American Culture: Significant Symbols of Campaign 1980

This contents is available in Studies in Visual Communication: https://repository.upenn.edu/svc/vol8/iss1/9 


\title{
Political Cartoons and American Culture: Significant Symbols of Campaign 1980*
}

\author{
Michael A. DeSousa and Martin J. Medhurst
}

In his classic anthropological journal, Tristes tropiques, Claude Lévi-Strauss describes what he calls an "extraordinary incident" resulting from his attempts to learn what members of an Amazon Indian tribe would do if presented with paper and pencil. Since the tribe had no written language, the anthropologist was surprised to note that the tribal chieftain began to scrawl furiously on his pad, producing a mass of unintelligible scribbles. At first Lévi-Strauss reasoned that the chief was simply aping the wavy lines which he had observed the anthropologist making during his daily journal entries. But upon observing the awed tribal reaction to the chief's apparently spontaneous grasp of writing, Lévi-Strauss reached a deeper conclusion: Without understanding specifically how writing worked, both the tribal chief and his followers did comprehend that these scribbles somehow contained tremendous power; the chief was simply feigning a grasp of this new power in an effort to solidify his authority over the tribe (Lévi-Strauss 1977: 333-339). Simple scribbles can often hold great significance for human beings.

This article addresses a very different class of scribbles, but like the products of the experiment noted above, they are equally problematic. We are not quite sure what the scribbles mean, but we are somehow certain they are important. We refer to that most neglected genre of political communication, the editorial cartoon. This article examines the American editorial cartoon from the vantage point of the 1980 presidential campaign. Our argument is twofold. First, we believe editorial cartoons provide a subtle framework within which to view the American political process and its players. Cartoons not only reflect our culture but also invite us to think about its constituent parts and their meaning for our own lives. Second, we believe the real significance of the political cartoon lies not in its character as propositional argument or as persuasion but in its ability to tap the collective consciousness of readers in a manner similar to religious rituals, civic ceremonies, and communal observances. Cartoons are important to the extent that they help to maintain the ties which identify us as one people.

Michael A. DeSousa is Visiting Lecturer and Martin J. Medhurst is Assistant Professor in the Department of Rhetoric, University of California, Davis. DeSousa's areas of research are television criticism and international communications. Medhurst's research includes work in rhetorical criticism, political communication, and film criticism. They are currently involved in research on methods of teaching visual literacy.

*An earlier version of this paper was presented at the 1981 San Dicgo Conference on Culture and Communication.
There are various ways in which this maintaining and identifying function can operate. We will discuss four possible options. But before moving on to our functional hypotheses, let us consider what others have said about political caricature, and in doing so distinguish more clearly our own views from those which once held sway and still, to some extent, find ready acceptance among contemporary scholars.

\section{The Nature and Significance of Caricature}

In this century three basic paradigms have appeared to explain the uses and effects of cartoons: the psychoanalytic, the sociological, and the rhetorical. Each model supplies useful insights within the bounds of its respective assumptions. In isolation, however, each fails to account for what we believe to be the central significance of the art-that cartooning is a culturecreating, culture-maintaining, culture-identifying artifact.

The psychoanalytic approach, for example, reminds us that symbolism is the heartbeat of caricature and that condensation and displacement play central roles in the production and interpretation of political cartoons. ${ }^{1}$ Ernst Kris, a leading exponent of this view, argues that "adult comic invention, and certainly the comic in its tendentious forms, helps in obtaining mastery over affects, over libidinal and aggressive tendencies warded off by the superego; the ego acting in the service of the pleasure principle is able to elude them by taking the path of comic expression" (1952:183). Cartoons, in other words, are merely the adult's way of displacing aggression through the adoption of a symbolic substitute.

The sociological paradigm moves outside of the mind and motives of comic inventors to stress societal structures which limit and enhance caricature, the symbolic resources available in such a society, and the potential meaning and uses of such symbology within specific sociopolitical contexts. The works of Streicher (1965-1966 and 1966-1967), Coupe (1966-1967 and 1969), and Alba (1966-1967) stand as exemplars of this perspective. As Streicher says, "caricature is a way of catching at a glance the meaning of an event, a person in the news, or a pictorial summary of a current power constellation" (1965-1966:1). Showing the interrelationships of people, events, and power is, from a sociological perspective, the primary function of political cartooning. 
The rhetorical approach borrows from both the psychoanalytic and sociological perspectives as well as from Gestalt psychology to comment on the interaction of creator, message, and audience. Within this framework Morrison (1969) has speculated on the image-making function of cartoons, Turner (1977) has explored the enthymematic structures of graphic satire, and Medhurst and DeSousa (1981) have advanced a typology for the language function of caricature. Though employing radically different approaches, each of these communications scholars operates from a similar assumption-graphic art has persuasive dimensions.

\section{Garicature and Popular Culture}

Editorial cartoons have been relatively neglected by scholars in political and cultural studies, and the failure of such scholars to take the political cartoon seriously may be traced in part to a fundamental bias against the popular arts. ${ }^{2}$ Popular arts, from one vantage point, are topics unworthy of serious examination or thought. A less extreme view is that although popular culture is an appropriate field of study, in many respects it offers only marginal or superficial insights into the real business of politics.

We can easily dismiss the first view but would do well to think seriously about the implications of the second. Robert Meadow typifies the latter when he writes:

Political cartoonists are in the difficult position of continuously criticizing, moving from issue to issue, but they must consider many elements only superficially. ... As elements of the popular culture they are the most explicitly political. But to the extent they offer only a passing chuckle rather than a deep reflection on government, political cartocns and comics offer limited political significance compared to other elements of the popular culture. [1980:203; emphasis added]

Meadow's generalization reflects one major perspective on the role of popular art in general and on political cartoons in particular. Such cartoons are easily dismissed because their apparent function, entertainment, appears peripheral to politics as a serious enterprise. Moreover, Meadow's observation may reveal an even more fundamental orientation to the field of political communication, an orientation which holds that only those communications which are effective in demonstrably changing beliefs, attitudes, or behaviors are politically significant. If this is the position adopted or implied, it is misleading insofar as it unnecessarily restricts the arena within which symbolism functions in a politically significant manner. A contrasting view, implicit in this essay, holds that sym- bolic interactions, which maintain but do not necessarily alter the political environment and its everchanging power relationships, serve an important sociopolitical function. James Carey refers to this clash of paradigms as the tension between a transmission and a cultural view of human communication. ${ }^{3}$

Cartoons, according to a cultural or ritual view, are attempts "not to provide information but confirmation, not to alter attitudes or change minds but to represent an underlying order of things, not to perform functions but to manifest an ongoing and fragile social process" (Carey 1975a:6). So defined, cartoons reveal a subtle yet powerful frame within which to characterize the American political process and its players. In contrast to Meadow's position, it is clear that political cartoons may, indeed, result in some deep reflection, if by reflection one means a mirroring, a reviewing, or a remembering of the dominant culture.

The power of the political cartoon lies not in the specific artist's intent or success at fostering change but in the degree to which, and the manner by which, the cartoonist taps the collective consciousness of readers and thereby reaffirms cultural values and individual interpretation of those values. The cartoonist does not create from whole cloth, but, instead, articulates a frame from the artist's unique percept to the shared experiences of the readers. The cartoon generally functions not as a change agent but as a statement of consensus, an invitation to remember cultural values and beliefs and, by implication, to participate in their maintenance.

If this cultural view of communication is correct, the political cartoon may indeed be "very powerful," as James David Barber hypothesizes in a Newsweek article (Adler et al. 1980), precisely because it argues for a prevailing view and functions as a statement of graphic opinion which maintains the political environment. But how might such a view be confirmed or refuted? An examination of what Gombrich calls the "cartoonist's armoury" (1963), his inventional storehouse, is a logical place to begin.

\section{The Cartoonist's Armoury}

What, for example, are the recurring sources to which cartoonists turn for daily inspiration? How deep are the reservoirs of cultural forms that can be tapped day after day? Our analysis revealed four major inventional resources: political commonplaces, literary/ cultural allusions, personal character traits, and transient situational themes. ${ }^{4}$ 
Political commonplaces are those topics which are readily available to any cartoonist working within the context of modern electoral politics. Such commonplaces include the state of the economy, foreign policy, national defense, the political process, and various dimensions of the electoral framework, such as campaigning, polling, voting, and special interests. Political commonplaces provide the daily grist for the cartoonist's mill. They form the core of political cartoons in the sense that one cannot create graphic caricature on a regular basis without some awareness of these predictable subthemes. To some degree, political commonplaces are the constituent parts which define politics as politics and which differentiate it from other aspects of American culture.

A second inventional source used by cartoonists is the literary/cultural allusion, by which we mean any fictive or historical character, any narrative form, whether drawn from legend, folklore, literature, or the mass media, which is used to frame a political event or issue. Such allusions are used to call attention to the contrasts between well-known fictions and contemporary political realities.

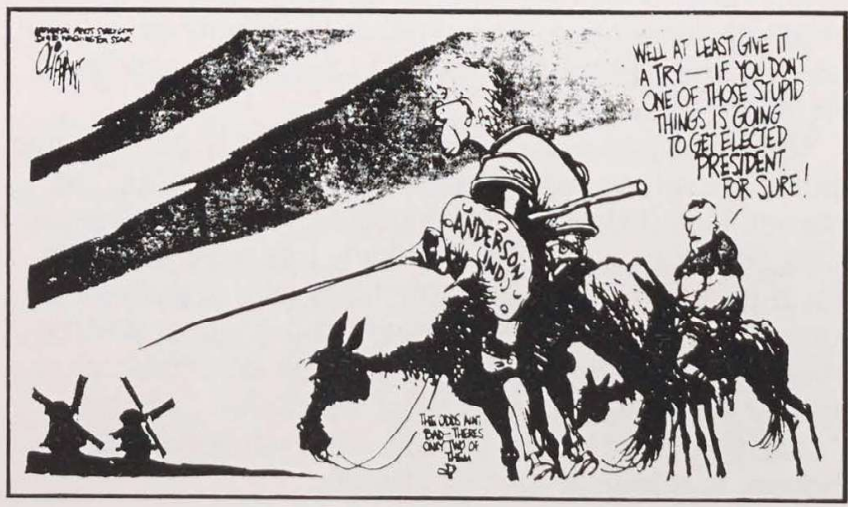

Figure 1 Patrick Oliphant, Washington Star, copyright 1980. (Reprinted with permission of Universal Press Syndicate. All rights reserved.)
For a cartoonist like Patrick Oliphant to portray John Anderson as Don Quixote preparing to tilt at windmills is to make a complex set of statements about Anderson, Oliphant's perception of Anderson, and the American public's evolving perception of the thirdparty candidate (see Figure 1). Yet it is the ambiguity of the allusion which is so problematic. Which dimensions of the literary character are being attached to Anderson? Is this Quixote the courageous man of principle fighting against all odds or Quixote the madman, foolishly tilting at windmills which can never be defeated?

The use of the literary/cultural allusion presumes that readers will be able to draw the connections between the political event (Carter at the Democratic Convention) and the fictive or cultural form (Custer's Last Stand) (see Figure 2). While most allusions involve simple historical events or literary forms which are collectively understood within United States society, elitist or esoteric allusions also appeared in campaign 1980 cartoons. For example, twice cartoonist Paul Conrad used the albatross imagery from Coleridge's The Rime of the Ancient Mariner to comment on political liabilities. In the fall of 1979 he pictured

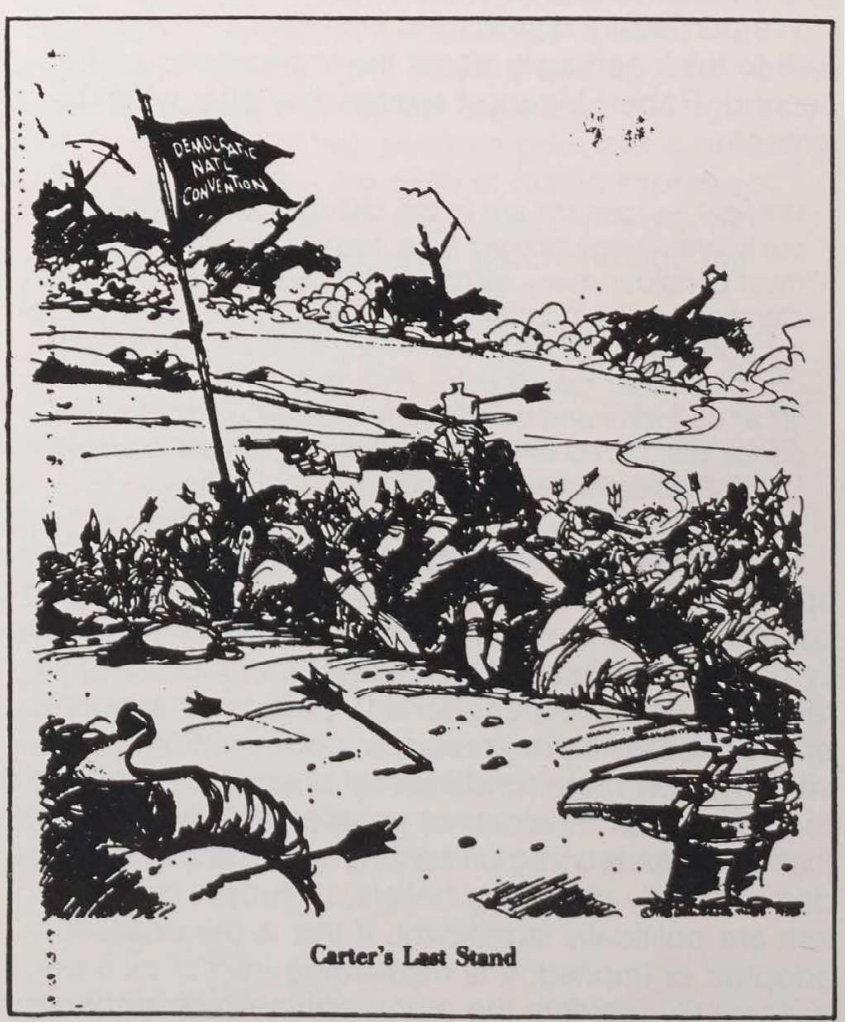

Figure 2 Paul Conrad, Los Angeles Times, copyright 1980. (Reprinted with permission.) 
Ted Kennedy collared by the albatross of Chappaquiddick, and in fall 1980 he burdened Jimmy Carter with the albatross of his Democratic rival for the party nomination (see Figure 3). The works of Shakespeare, Homer, Picasso, Cervantes, and Melville were all borrowed by cartoonists seeking to draw comparisons between an elite art form and a contemporary political event or figure.

These elite allusions stand in strong contrast to the many popular arts - television, film, legends-which were alluded to by cartoonists during the 1980 campaign. Our sample of cartoons revealed that wellknown films of yesterday (see Figure 4) and today (see Figure 5) were the popular art most used by editorial cartoonists. Films such as The Black Stallion, The Empire Strikes Back, Kramer vs. Kramer, and Raise the Titanic, and, of course, humorous references to candidate Reagan's films (see Figure 6), were used as vehicles for political commentary. The question remains, however, whether either popular or elite allusions were the more powerful graphic messages
A cartoon employing the literary/cultural allusion, then, derives its impact not solely from the political event or figure it treats but also from the interaction of that person/event with an identifiable fiction or a historical event. To decode the cartoon in line with the cartoonist's intent requires familiarity with the fictive or cultural form to which it refers.

The cartoonist's third inventional source draws upon popular perceptions of the politician's personal character. Such traits as intelligence, honesty, age, morality, charisma, and leadership can be portrayed through a combination of image and caption. The exaggerated portrayal of these traits forms the basis of what we popularly know as caricature, a term derived from the Italian caricare, "to charge or overcharge with meaning."

But no traits, whether physical or psychological, can be wholly manufactured by the cartoonist and imposed on the politician. For a caricature to be a viable amplification, the exaggeration must first be based on a collective perception that the cartoon reflects some inner truth about the political figure. (See Table 1, which shows the percentage of exaggerated

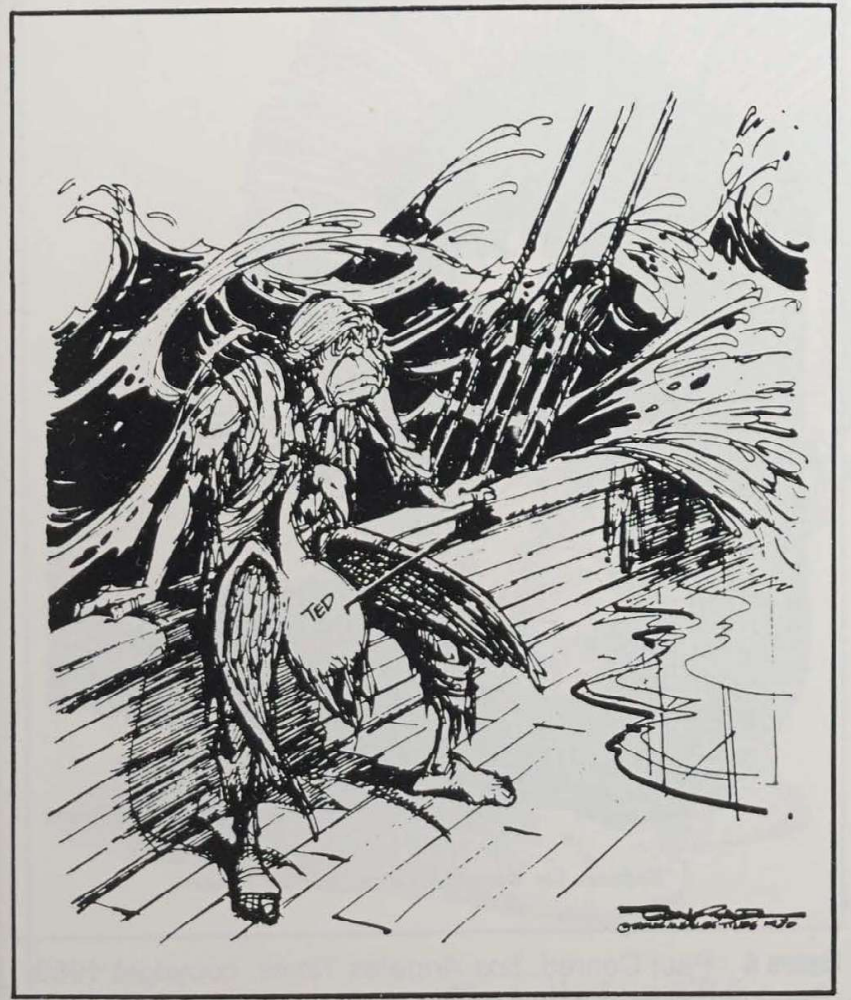

Figure 3 Paul Conrad, Los Angeles Times, copyright 1980 (Reprinted with permission.)

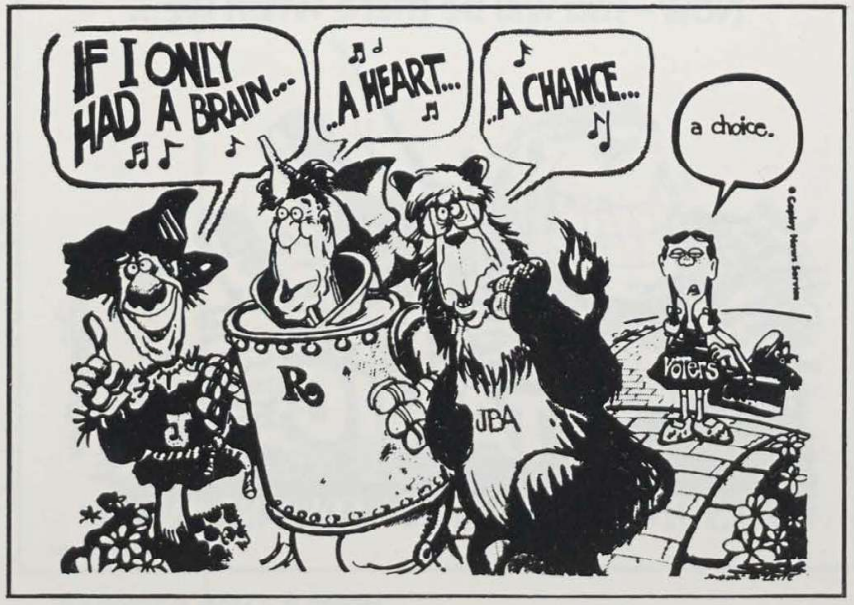

Figure 4 Steve Sack, Fort Wayne Journal-Gazette, copyright 1980. (Reprinted with permission.) 
Table 1 Exaggerated Features of Political Candidates in Campaign 1980

\begin{tabular}{|c|c|c|c|c|c|c|c|c|}
\hline & Carter & Reagan & Anderson & Kennedy & Brown & Connally & Bush & Ford \\
\hline \multicolumn{2}{|c|}{$\begin{array}{l}\text { Number of cartoons } \\
\text { in which portrayed (236) }\end{array}$} & (153) & $(64)$ & (94) & $(16)$ & (7) & (11) & $(16)$ \\
\hline \multirow{7}{*}{$\begin{array}{l}\text { Exaggerated } \\
\text { features } \\
\text { as } \\
\text { percent of } \\
\text { total } \\
\text { representation }\end{array}$} & $\begin{array}{l}\text { Smile } \\
26.7 \%\end{array}$ & $\begin{array}{l}\text { Hair } \\
88.9 \%\end{array}$ & $\begin{array}{l}\text { Glasses } \\
98.4 \%\end{array}$ & $\begin{array}{l}\text { Hair } \\
69.1 \%\end{array}$ & $\begin{array}{l}\text { Nose } \\
43.8 \%\end{array}$ & $\begin{array}{l}\text { Nose } \\
71.5 \%\end{array}$ & $\begin{array}{l}\text { Shape of } \\
\text { face } \\
54.5 \%\end{array}$ & $\begin{array}{l}\text { Body } \\
\text { shape } \\
50.0 \%\end{array}$ \\
\hline & $\begin{array}{l}\text { Lips } \\
20.8 \% \\
\end{array}$ & $\begin{array}{l}\text { Facial } \\
\text { wrinkles } \\
56.2 \%\end{array}$ & $\begin{array}{l}\text { Jaw } \\
\text { line } \\
14.1 \%\end{array}$ & $\begin{array}{l}\text { Puffy } \\
\text { face } \\
64.9 \%\end{array}$ & $\begin{array}{l}\text { Chin } \\
43.8 \%\end{array}$ & $\begin{array}{l}\text { Chin } \\
71.5 \%\end{array}$ & $\begin{array}{l}\text { Nose } \\
36.4 \%\end{array}$ & $\begin{array}{l}\text { Bald } \\
\text { head } \\
50.0 \%\end{array}$ \\
\hline & $\begin{array}{l}\text { Teeth } \\
20.3 \%\end{array}$ & $\begin{array}{l}\text { Clothes } \\
9.2 \%\end{array}$ & $\begin{array}{l}\text { Hair } \\
9.4 \%\end{array}$ & $\begin{array}{l}\text { Chin } \\
59.6 \%\end{array}$ & $\begin{array}{l}\text { Clothes } \\
31.3 \%\end{array}$ & $\begin{array}{l}\text { Clothes } \\
42.9 \%\end{array}$ & $\begin{array}{l}\text { Crooked } \\
\text { jaw } \\
27.3 \%\end{array}$ & $\begin{array}{l}\text { Clothes } \\
25.0 \%\end{array}$ \\
\hline & $\begin{array}{l}\text { Nose } \\
16.9 \%\end{array}$ & $\begin{array}{l}\text { Mouth } \\
9.2 \%\end{array}$ & $\begin{array}{l}\text { Gestures } \\
9.4 \%\end{array}$ & $\begin{array}{l}\text { Body } \\
\text { shape } \\
35.1 \%\end{array}$ & $\begin{array}{l}\text { Hair } \\
25.0 \%\end{array}$ & $\begin{array}{l}\text { Face } \\
14.3 \%\end{array}$ & $\begin{array}{l}\text { Eyebrows } \\
18.2 \%\end{array}$ & $\begin{array}{l}\text { Shape of } \\
\text { face } \\
18.8 \%\end{array}$ \\
\hline & $\begin{array}{l}\text { Size } \\
12.3 \% \\
\end{array}$ & $\begin{array}{l}\text { Nose } \\
8.5 \%\end{array}$ & $\begin{array}{l}\text { Nose } \\
6.3 \%\end{array}$ & $\begin{array}{l}\text { Nose } \\
6.4 \%\end{array}$ & $\begin{array}{l}\text { Speech } \\
25.0 \%\end{array}$ & & $\begin{array}{l}\text { Clothes } \\
9.1 \%\end{array}$ & \\
\hline & $\begin{array}{l}\text { Clothes } \\
3.8 \%\end{array}$ & $\begin{array}{l}\text { Smile } \\
6.5 \%\end{array}$ & $\begin{array}{l}\text { Smile } \\
1.6 \%\end{array}$ & $\begin{array}{l}\text { Glasses } \\
3.2 \%\end{array}$ & & & & \\
\hline & $\begin{array}{l}\text { Hair } \\
3.0 \%\end{array}$ & & & & & & & \\
\hline
\end{tabular}

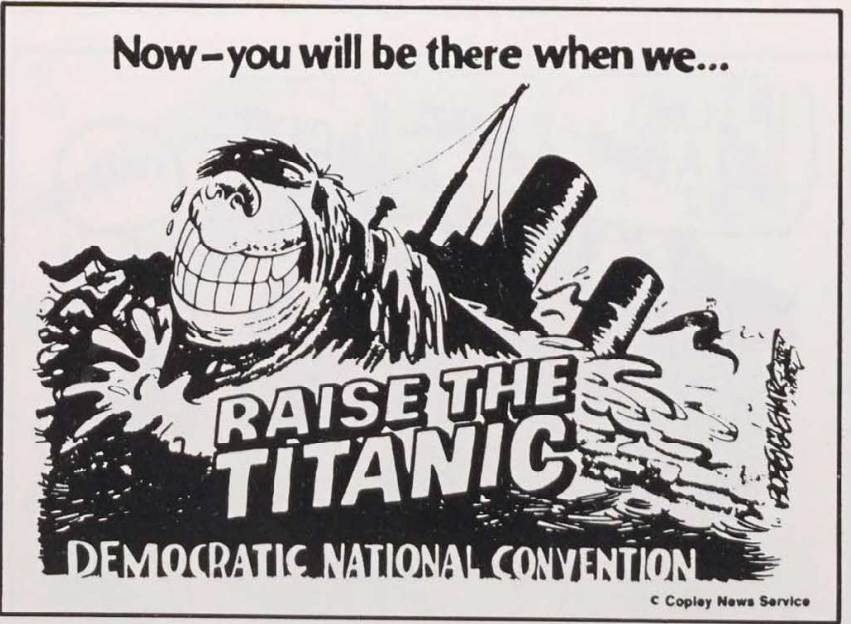

Figure 5 Bob Englehart, Dayton Journal Herald, copyright 1980. (Reprinted with permission.)

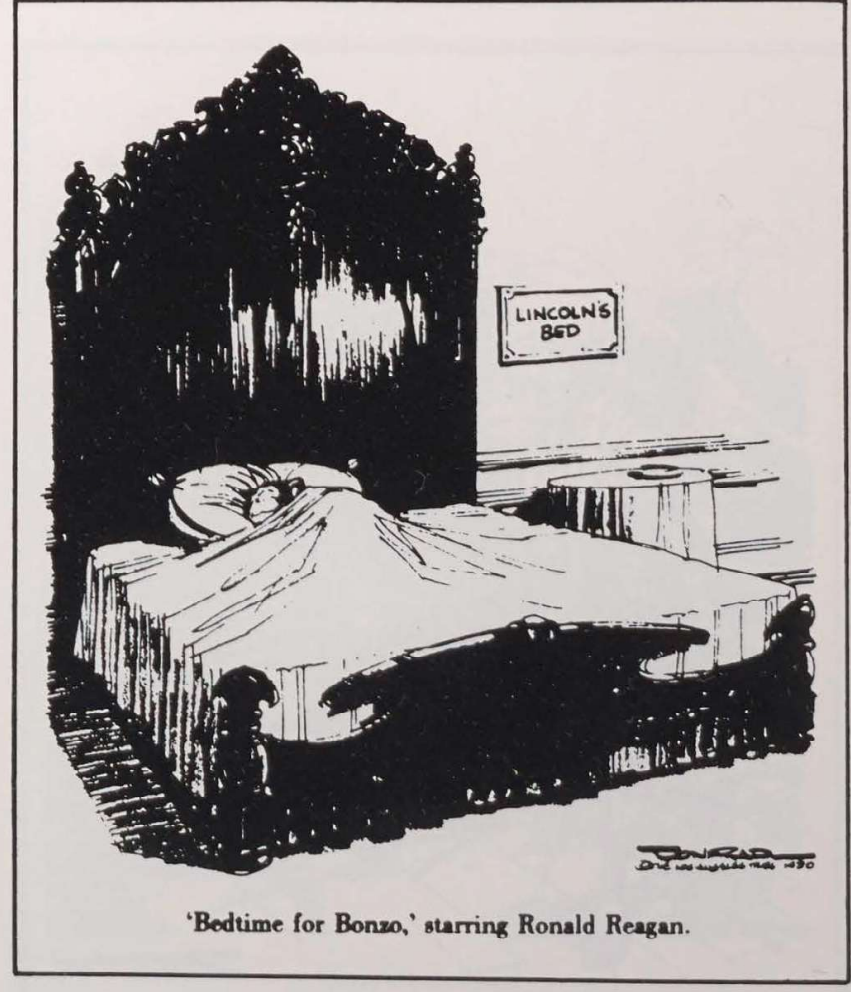

Figure 6 Paul Conrad, Los Angeles Times, copyright 1980. (Reprinted with permission.) 
features for each candidate in our sample.) Herblock's early renderings of then Vice-President Nixon, complete with five o'clock shadow, did more than reflect the physical reality of Nixon's unfortunate combination of heavy beard and transparent complexion; they reflected a shared perception among many Americans that Nixon was indeed a shady character ("Tricky Dick"), the sort of shyster who could be revealed by the con man's blue beard. Similarly, Conrad's artful lampooning of Ronald Reagan neatly combines both widely perceived ideological traits (conservatism, chauvinism) and physical traits (wrinkled face, pompadour hairstyle). Conrad does not invent a Reagan persona so much as he gives expression to the Reagan persona resident in the political consciousness of at least some of the electorate (see Figure 7 ).
The following examples also illustrate that effective caricature must do more than simply reflect an apparent physical reality, an obvious physical trait. In Figure 8 Oliphant uses the visual icons associated with old age (cane, shawl, wheelchair, craggy features), as well as caption, to comment editorially on Reagan's advanced years and, by extension, the politically outdated mentality consistent with those advanced years. Bill Schorr also uses a perceived trait in his consideration of Kennedy's morality (see Figure 9). The cartoonist establishes a graphic context via a political commonplace (baby-kissing in campaigns), then violates the expectation of the commonplace by placing an untoward action within the frame. The result is a wry commentary on a suspected character trait of the candidate.

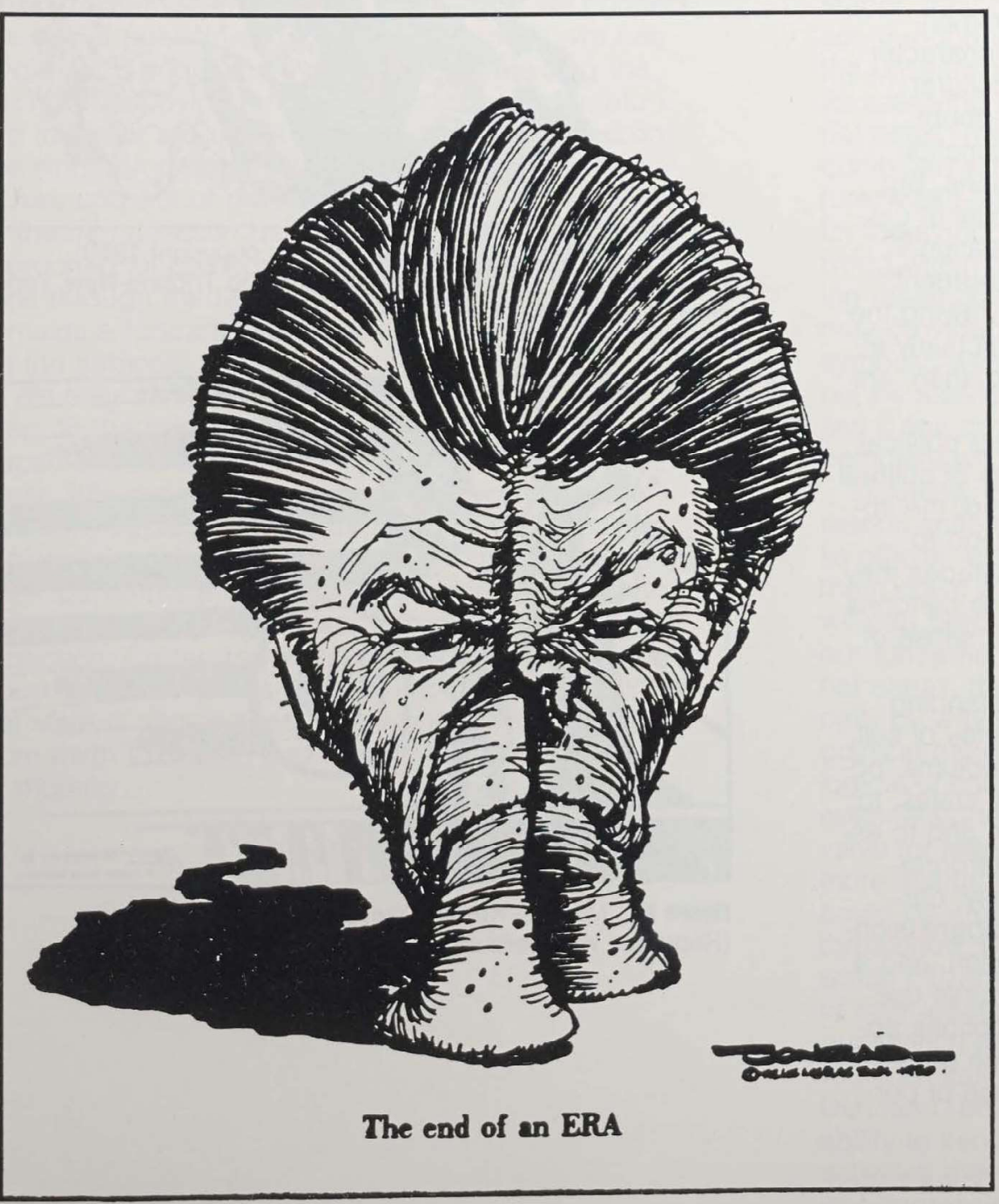

Figure 7 Paul Conrad, Los Angeles Times, copyright 1980. (Reprinted with permission.) 
Timely and transient situations which appear unexpectedly during the course of a campaign constitute a fourth inventional resource for political cartoonists. Such events may have an immediate impact and spark short-term controversy, but they seldom endure beyond their immediate historical context. It is this truism which makes so many historical cartoons incomprehensible to modern readers (Sproule 1980:348). These transient events take their meaning, in large part, from the context of the headlines, the now.

In Figure 10 the reader is required to be cognizant of the antics of Billy Carter and the "Billygate" affair to understand the cartoonist's message. The short-lived flap over Reagan's "duck joke" is yet another example of the role which transient tempests-inteapots play as inspirations for the cartoonist's daily musings (see Figure 11). The gaffe, the faux pas, the off-the-cuff comment add unexpected and welcome variety to the cartoonist's repertoire.

The inventional storehouse-political commonplaces, literary/cultural allusions, personal character traits, and situational themes-reveal the cultural premises from which cartoonists work. No doubt many cartoonists intend their creations to function persuasively, to change audience perceptions. But research reveals that the persuasive potential of cartoons is often vitiated by audience interpretation. ${ }^{5}$ That which the cartoonist intends is not congruent with what the audience understands from viewing the caricature. Cartoons, it seems, are not particularly effective as agents of change. In what sense, then, are they effective or significant?

As indicated earlier, the importance of the political cartoon lies in its ability to maintain a sense of cultural coherence and personal identity. To this end, the important question is not what cartoonists intend to communicate or what beliefs, values, or attitudes they hope to change, but rather how readers use cartoons to understand their culture or maintain their sense of identity within it.

We offer four possible options for understanding how readers use cartoons to maintain a sense of self, others, and society. Like other ritualistic mediums, political cartoons are used to express internal states, to achieve an understanding of cultural order, and to establish touchstones against which other interpretations of reality can be measured. Specifically, cartoons serve an entertainment function, an aggressionreduction function, an agenda-setting function, and a framing function. Different people will of course use cartoons in different ways, but these four options appear to be the most likely alternatives for the preservation of cultural ideals and the maintenance of personal identity.

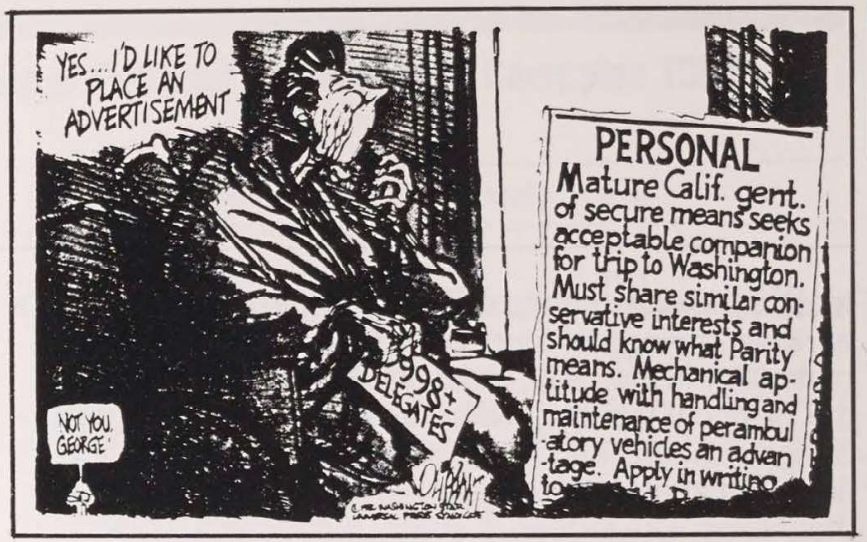

Figure 8 Patrick Oliphant, Washington Star, copyright 1980. (Reprinted with permission of Universal Press Syndicate. All rights reserved.)

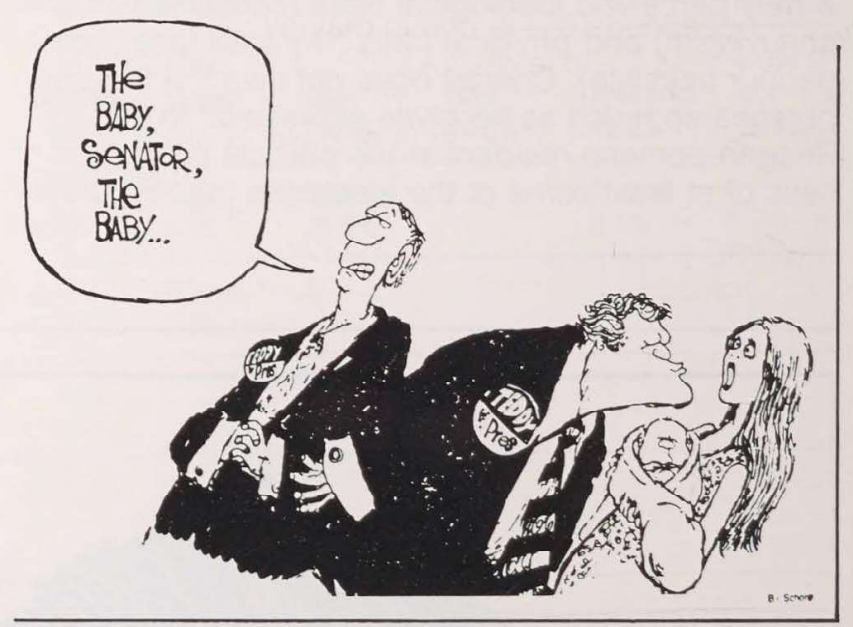

Figure 9 Bill Schorr, Chicago Tribune, copyright 1979. (Reprinted with permission of the Chicago Tribune-New York News Syndicate, Inc.)

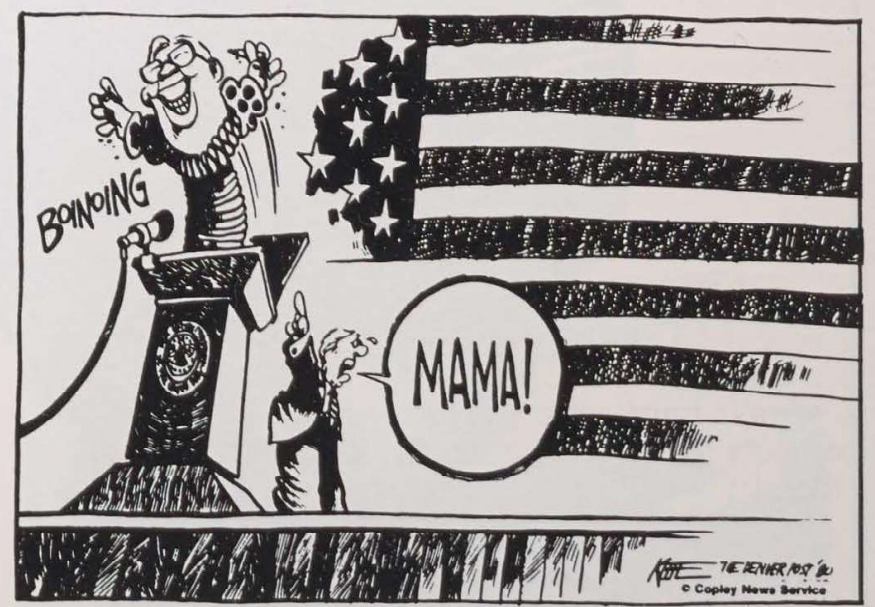

Figure 10 Michael Keefe, Denver Post, copyright 1980. (Reprinted with permission.) 


\section{The Entertainment Function}

We would commonly say that political cartoons give us entertainment, that they make us laugh at situations and individuals (Gruner 1978:149-155). But the covering term "entertainment" does little to explain how cartoons serve the consumers of these graphics. To say that political cartoons are entertaining because they are comic is again simplistic, but at least this descriptor places the cartoon within the critical framework of the comic. In fact, a brief retreat to classical conceptions of the comic may even be useful.

Ever since Aristotle discussed comedy as counterpart to tragedy, one characterization of the former has been the depiction of the acts of baser (common) men for the purpose of providing moral education for the audience (McKeon 1941:1459). If, for example, we attend a comic play or read a comic poem in which someone very much like us suffers shame or ridicule because of some improper act, we have an opportunity to learn from the mistakes. If we connect the social punishment with the impropriety, we can avoid such punishment ourselves by avoiding the wrongful act (lying, cheating, infidelity, vanity, etc.). We laugh or smile at the social disgrace visited on the sinner in recognition of the same flaws in ourselves and out of gratitude that we are not the victims of the moral lesson being taught. This strong sense of the comic, of comedy as social or moral education, runs through medieval and Renaissance thought ${ }^{6}$ and remains a fundamental tenet of contemporary writing on the subject.

We may think of the political cartoon as comic, then, to the degree that it portrays and critiques, in capsule form, basic human failings. The actors in these little dramas, however, are not willing players. They are those public figures suspected of moral or ethical wrongdoing, duplicity, hypocrisy, or stupidity. Their punishment is ridicule through portrayal on the editorial page in some compromising or unflattering depiction: Carter as inept clown or Reagan as ingenuous liar (see Figures 12 and 13). The reader's internal state is transformed as the comic function moves from mirth to morals and, finally, to a cultural sense of morality.

\section{The Aggression-Reducing Function}

The ways in which the apparently powerless succeed in deflating the apparently powerful via symbols indicate the tremendous stock we place in the destructive potential of symbolic forms (Jaffe 1977:260-261). The cruel rhymes of childhood, the effigy, and the caricature are reminders that although sticks and stones may break bones, symbols, when wielded effectively, may inflict even greater punishment.

That the relationship between the governing and the governed is less than amicable is a political truism. We are ambivalent about our national leaders, at once needing their leadership while resenting our dependence on them. That our leaders do influence our lives is also a political truism. Taxes are raised, services are cut, and young men prepare for war based on the decisions of those individuals we know as leaders.

When citizens object to actions taken by a political leader, they can act instrumentally against that person through the ballot box and the recall petition. But the unseating of a political leader may not be nearly as satisfying as his graphic persecution on the editorial page. The vigor of First Amendment protection, combined with the unlimited creativity of visual caricature, make the political cartoon a near-perfect vehicle for the symbolic denigration of a politician. Since the world within the cartoon frame need bear only passing resemblance to everyday reality, visual images may provide readers with more fanciful and stark symbolic weapons than do verbal symbols. One need not be satisfied with calling a despised senator an ass if one can enjoy a visual depiction of the offender complete with ears and tail.

In reality, few citizens will ever take effective instrumental action against a deceitful or incompetent public official. We must usually be satisfied with bringing them down a peg or two via the symbolic derogation we can practice as symbol users. Besides satisfying our fundamental need as humans to express our inner states, the ability to channel aggression symbolically by way of the political cartoon may entail certain political benefits or harms, depending on one's ideological orientation. As forms of communal criticism, editorial cartoons may provide an outlet, a safety valve for protests which might otherwise surface in more instrumental forms. The stability of a regime, it could be argued, might be furthered, rather than threatened, by the provision of channels through which citizens could participate in the symbolic killing of their leaders. For example, in the Soviet Union the publication Krokodil features editorial cartoon satire, within limitations, of the Soviet system. As Hugh Duncan (1962:376-380) has cogently argued, the ability to vent hostility in socially approved symbolic activities may lessen or even negate the need for violent aggression. 


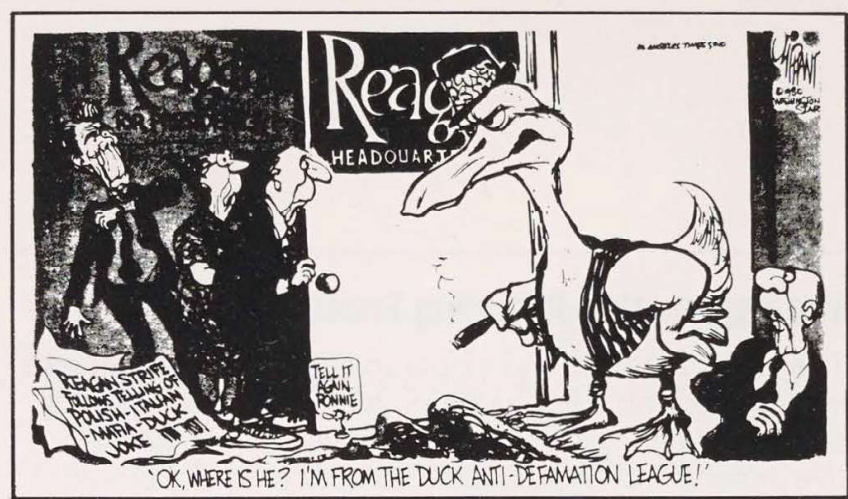

Figure 11 Patrick Oliphant, Washington Star, copyright 1980. (Reprinted with permission of the Universal Press Syndicate. All rights reserved.)

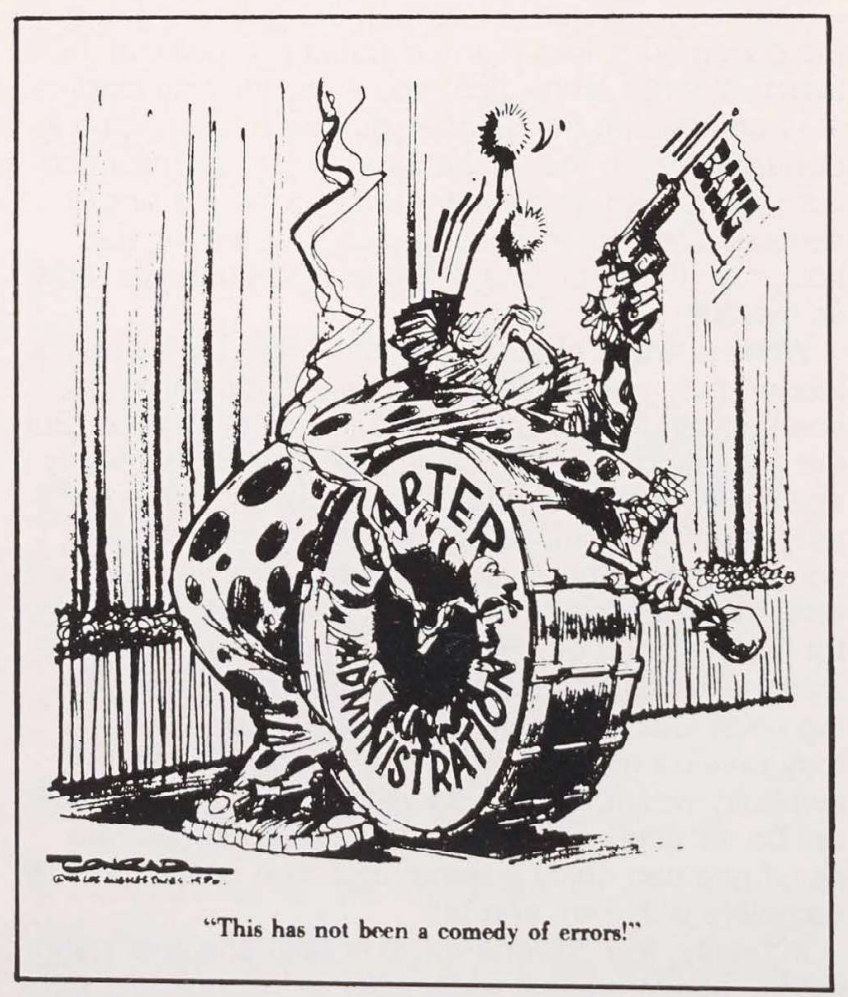

Figure 12 Paul Conrad, Los Angeles Times, copyright 1980. (Reprinted with permission.)

The political cartoon may thus qualify as one very understated way for some members of a society to channel collectively their hostility toward political leaders. Cartoons are successful vehicles for symbolic aggression to the degree that reader satisfaction is achieved within the dramatic world of the caricature. Cartoons which suggest that Carter or Reagan should be carted out of town on a rail are not preludes to some later satisfaction, such as the actual deportation of the victim. The cartoon is not a model for subsequent action, but an act unto itself, a symbolic act. The cartoon, as a collective fantasy, is functional for its readers to the degree that it provides them with some sense that the guilty have been punished, thereby bringing to the cartoon consumer an internal equilibrium and also supplying a continuum between cultural ideals and symbolic satisfactions.

\section{The Agenda-Setting Function}

Another function of the political cartoon results from its dependence on timeliness for much of its editorial impact. Although selected editorial cartoons may indeed speak to universal audiences with timeless messages, most political caricatures are invariably rooted in the now, in today's headlines. It is precisely the characteristic of fixed temporal context which so often renders cartoons from even the recent past insignificant. For example, the short-lived controversy generated by Ronald Reagan's ethnically offensive duck joke typifies the cause célèbre whose meaning might well escape the cartoon reader of the near future. Similarly, a political cartoon commenting on Abscam or the Billygate affair months after the events took place would appear lifeless and out of context. Yet it is precisely the cartoon's dependence on the political present which makes it an important index to the major issues of the day.

Political cartoons may contribute to the agenda-setting generally attributed to the major media in the sense that they provide readers with some sense of the most significant issues, events, or topics. ${ }^{7}$ Is a candidate's wife, religion, or family an important issue in the campaign, part of the agenda? One barometer might be whether the person or issue regularly preoccupies the major cartoonists since they are supposedly such sensitive reflectors of society's most important political issues (DeSousa 1981).

To the degree that this mirroring eventually succeeds in bringing to public discussion certain issues, the political cartoon may participate in what NoelleNeumann has tendered as the powerful role of mass media in shaping perceptions of "public opinion" (1973:67-112 and 1974:43-51). Agenda-setting, in this characterization, takes on much more significance than simply assigning topics in terms of their importance. Rather, the assignment of significance itself may result in greater public discussion, which, in turn, may result in attitudinal changes among participants in the discussion. That a topic is declared important is the first step toward its thorough discussion, a discussion which will eventually win or lose adherents for the issue at hand. Agenda-setting in the political cartoon may be conceptualized as one small but useful step toward identifying public issues. 


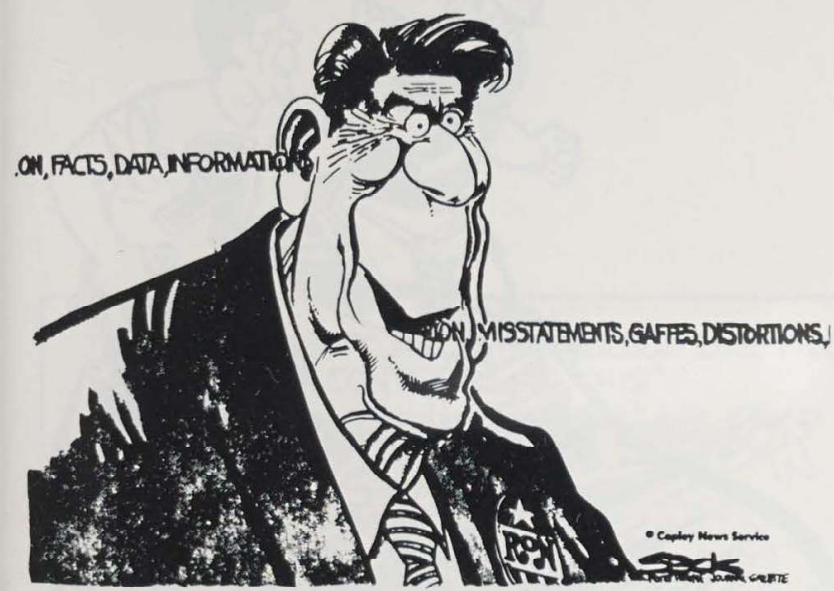

Figure 13 Steve Sack, Fort Wayne Journal-Gazette, copyright 1980. (Reprinted with permission.)

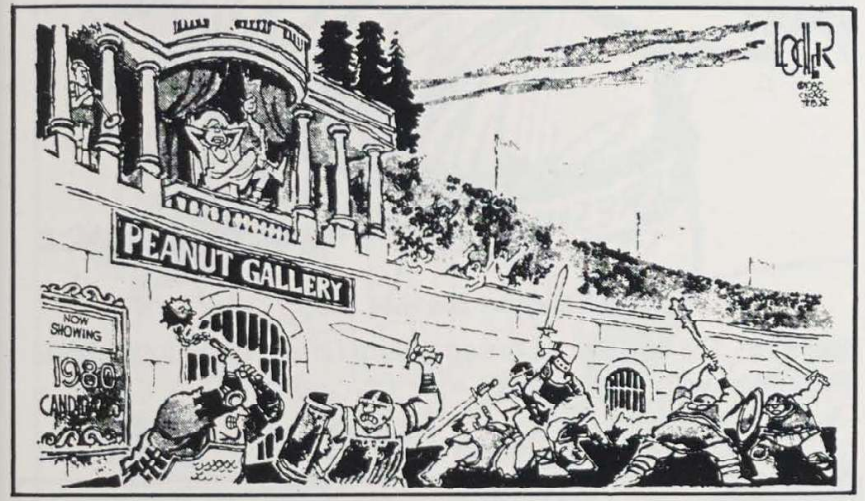

Figure 14 Dick Locher, Chicago Tribune, copyright 1980. (Reprinted with permission.)

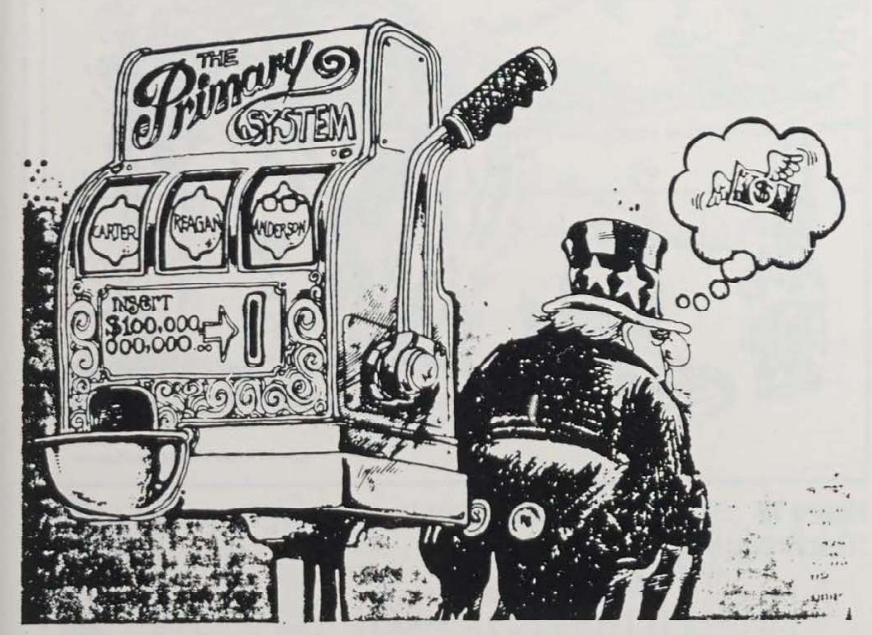

Figure 15 Steve Sack, Fort Wayne Journal-Gazette, copyright 1980. (Reprinted with permission.)

\section{The Framing Function}

A final probable function of the political cartoon derives from the nature of caricature itself, namely, as a highly condensed form of expression. Unlike the comic book illustrator or the strip cartoonist, the editorial caricaturist does not have the luxury of unfolding imagery in successive panels. He usually has only one frame with which to work, so the efficient use of forms within that frame is essential if the artist is to achieve the desired end. Editorial artists must achieve a concrete understanding, a Verstehen, with the reader almost immediately. To achieve this the cartoonist must concoct imagery that is at once compelling and powerful, drawing frequently from potent symbols within the political and cultural mythology.

This condensed nature of the political cartoon equips it for the reduction of complex issues into single visual designs. The cartoon functions, as Gombrich (1963) has written, to "give us the satisfaction of pretended insight." By reducing a complex issue or event to a simple metaphorical form, the political cartoon provides the reader with an attractive illusion of understanding that can serve as a touchstone for subsequent thought or action. For example, while the presidential primary system is anything but a simple process, cartoon characterizations of it presume to discover its essence, likening it to a beauty contest or a game of chance. Such cartoons do not unpack the actual usefulness or shortcomings of the system but instead offer a distilled message which is attractive because it provides perspective without the effort of personal investigation (Graber 1980:122-123). It is the enactment of a ritual that calls for a stock response. But like all rituals, it calls forth a response that can lead, in time, to deeper insight and understanding.

Our study of political cartoons from the 1980 campaign reveals nine clearly identifiable clusters of metaphors which were used to condense or characterize specific political events such as the primaries, conventions, and debates. Such clusters, or root metaphors, provide a critic with some sense of the dominant popular frameworks used to express American orientations to politics. Major root metaphors for the 1980 campaign included:

1 Campaign as combat/battle (Figure 14)

2 Campaign as gamble (Figure 15)

3 Campaign as media event (Figure 16)

4 Campaign as double-bind/nonchoice for voters (Figure 17)

5 Campaign as race (Figure 18)

6 Campaign as circus (Figure 19)

7 Campaign as beauty contest (Figure 20)

8 Campaign as sport/game (Figure 21)

9 Campaign as mudslinging/dirty business (Figure 22) 


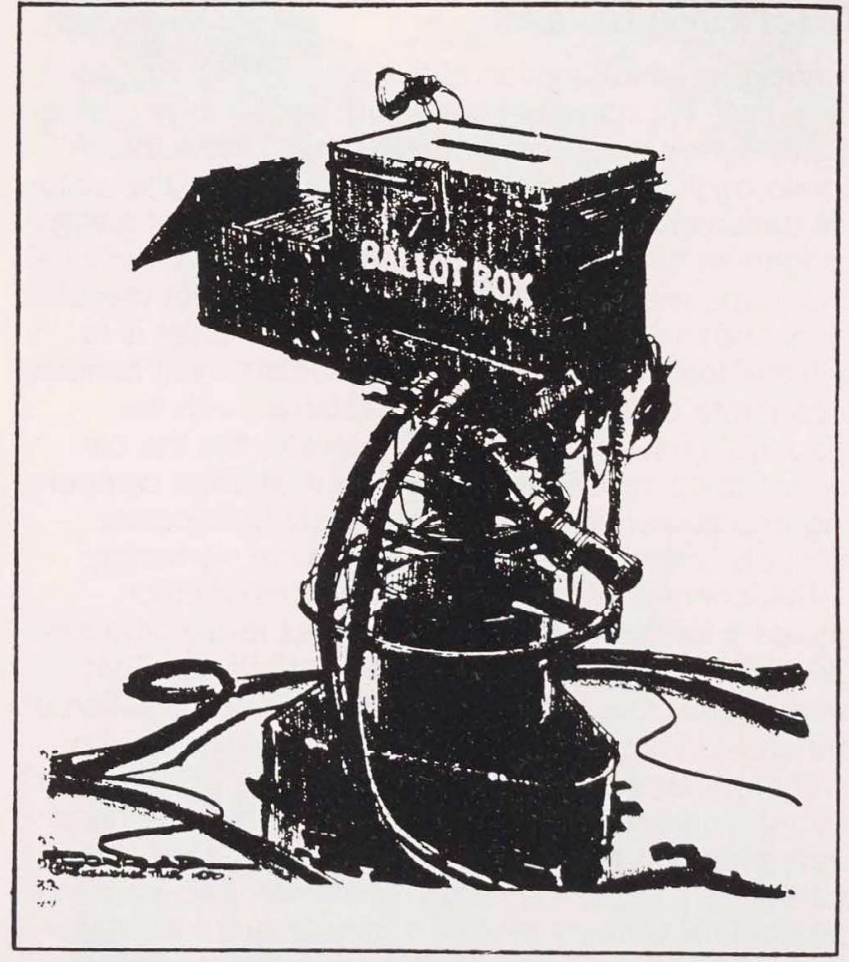

Figure 16 Paul Conrad, Los Angeles Times, copyright 1980. (Reprinted with permission.)

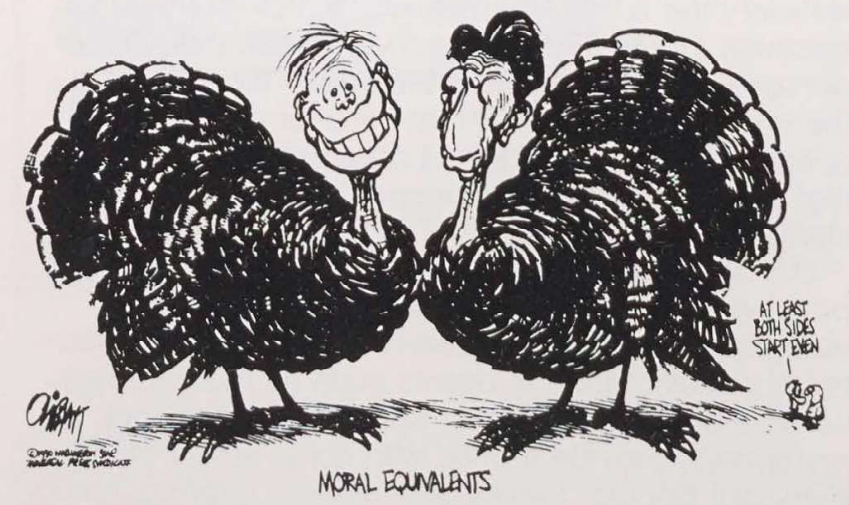

Figure 17 Patrick Oliphant, Washington Star, copyright 1980. (Reprinted with permission of Universal Press Syndicate. All rights reserved.)

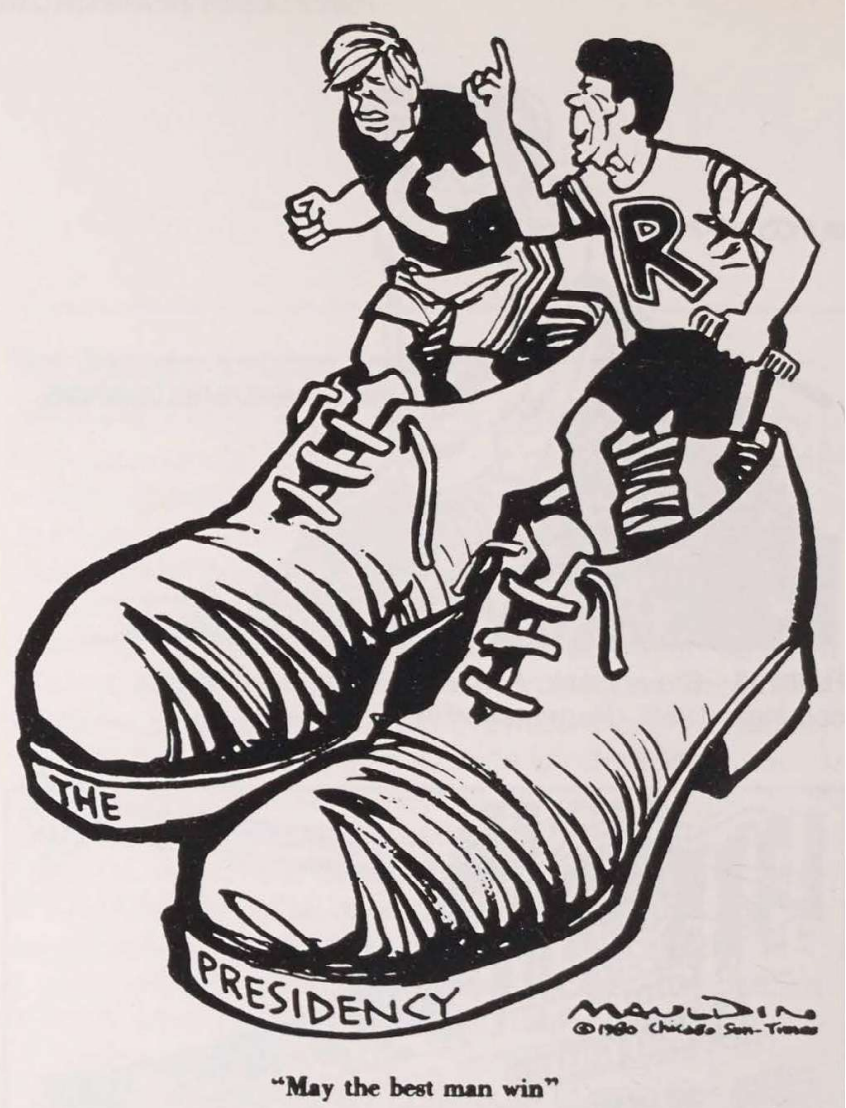

Figure 18 Bill Mauldin, Chicago Sun-Times, copyright 1980. (Reprinted with permission.)

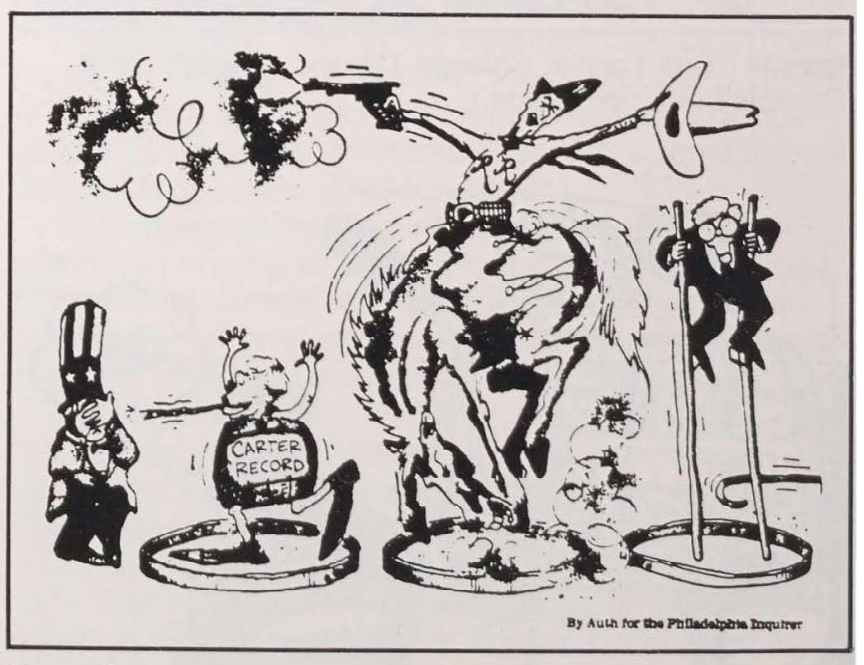

Figure 19 Tony Auth, Philadelphia Inquirer, copyright 1980. (Reprinted with permission.) 


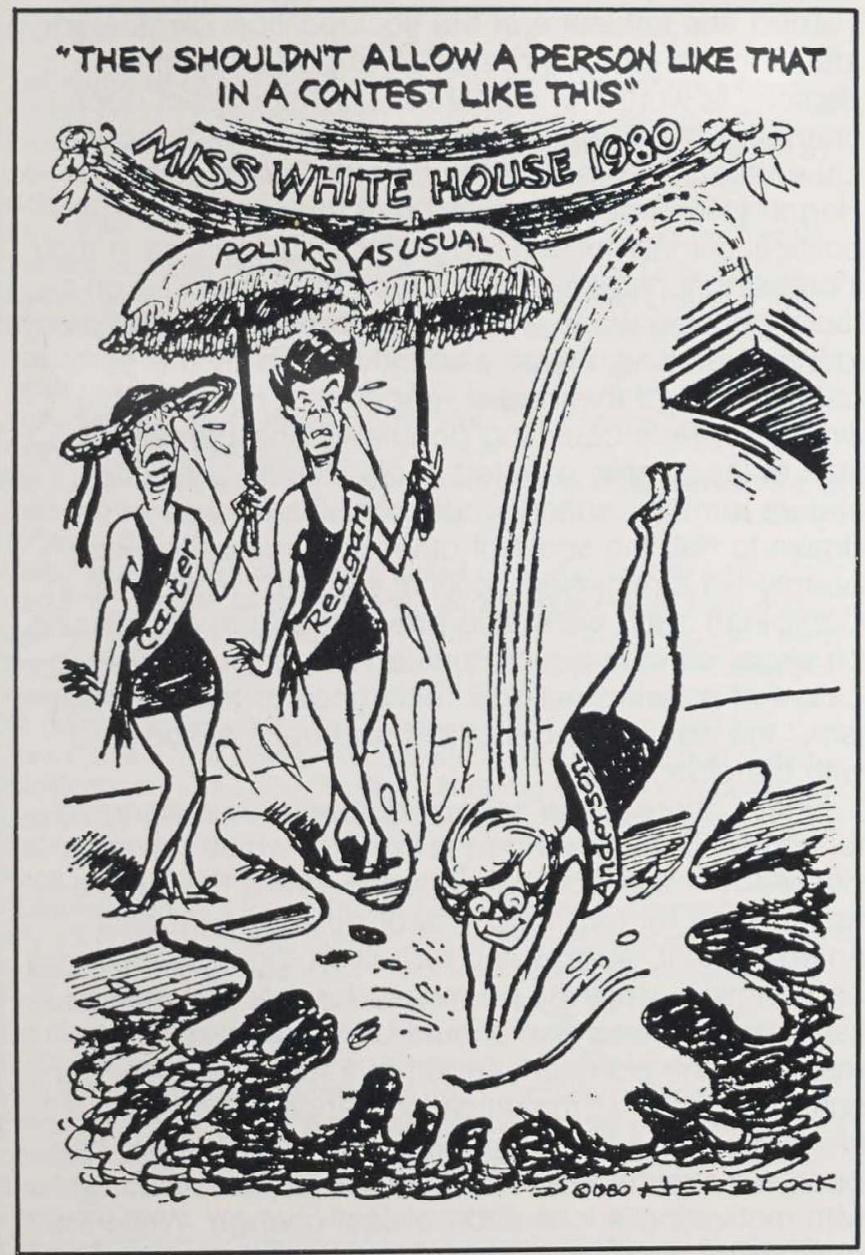

Figure 20 Herblock, Washington Post, copyright 1980. (Reprinted with permission.)

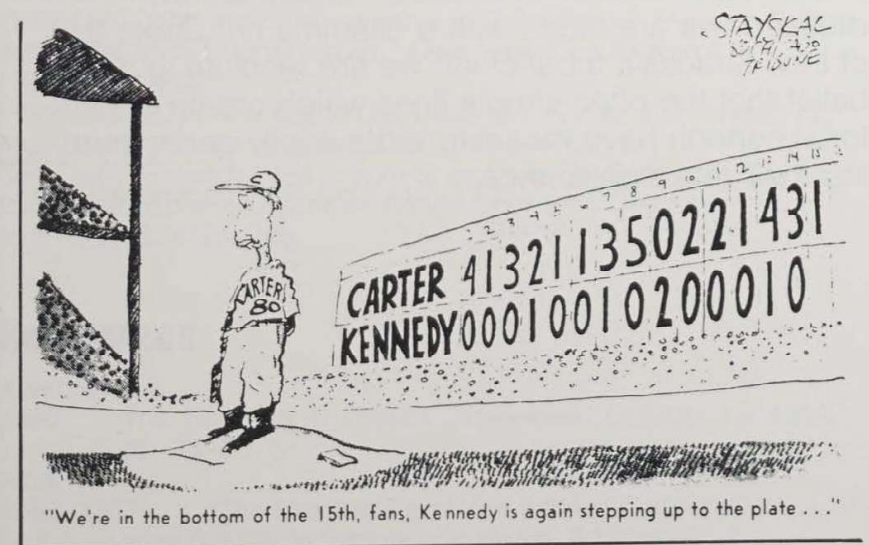

Figure 21 Wayne Stayskal, Chicago Tribune, copyright 1980. (Reprinted with permission.)

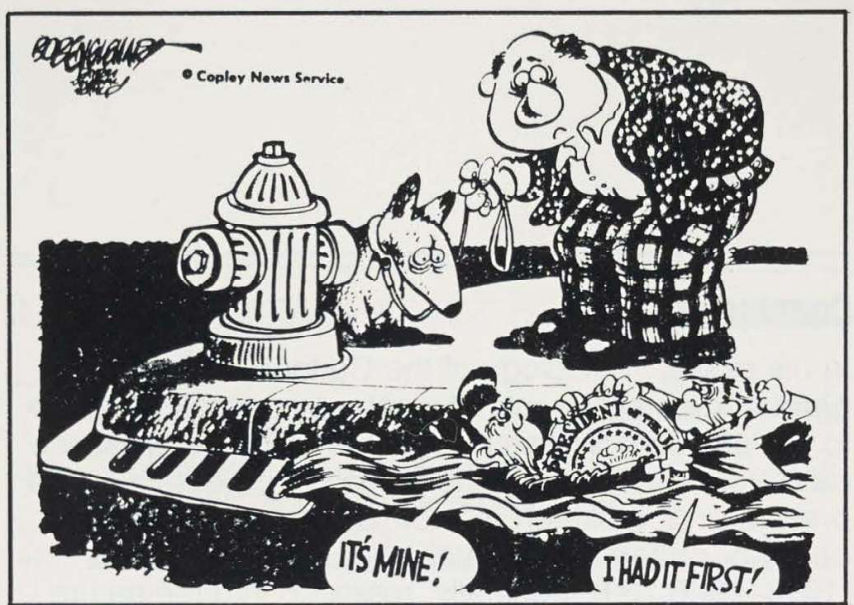

Figure 22 Bob Englehart, Dayton Journal Herald, copyright 1980. (Reprinted with permission.)

The idea of cartoon as frame for events and issues is consistent with media research that maintains that the role of various media increases when the topic in question is one with which the consumer has little personal experience. One may not need the media to help conceptualize inflation because it is experienced daily, but one is likely to be dependent on the media to give some sense of the situation in Iran or the United Nations because these topics are removed from immediate experience. Similarly, the political cartoon, as a message system within a major medium (newspaper), serves to provide readers with capsule characterizations of complicated issues. Although often simplistic characterizations, they are nevertheless attractive, as they rely on familiar forms to make metaphorical connections. To define the American presidential campaign as a dog show does not illuminate the campaign process, but it does provide a handle for individuals seeking escape from its inherent confusion. As a touchstone for further comparison and contrast, the framing function of cartoons serves a useful purpose. 


\section{Conclusion}

In his essay, "Sociology of the Cartoon," Emory Bogardus traced the roots of what we now call cartoons to the preliminary sketches prepared by Renaissance painters. He states that the cartoon was essentially "a pre-drawing, a sketch, something roughly depicting behavior patterns; not details but general features" (1945-1946:139). Ironically, research into the nature and function of the political cartoon is similarly unfinished and preliminary. To maintain that the American political cartoon is part of American culture is, in itself, a useless generality. What is needed instead, aside from a long-sought specific conception of culture, is a description of the roles played by cartoons as communicative forms within the culture. Clifford Geertz provides a lead when he writes that "culture consists of socially established structures of meaning," which is to say that culture can be defined as the totality of symbol systems used by a people in their drive to create and sustain shared meaning (1973:12). Actually to accept the political cartoon as a largely visual symbol system would be to pose a host of important research questions.

First, an effort must be made to determine whether an identifiable iconic vocabulary exists for cartoonists and their readers. To what degree does political cartooning, as communication, require a body of stock images and themes? As Dennis and Dennis (1974) have argued, the national syndication of political cartoons in the 1920s required that cartoonists use "uniform symbols for national appeal." Artistic creativity had to be sacrificed for the demands of the newspaper as national mass medium. As a result, the tophatted plutocrat, Uncle Sam, and the bloated, corrupt politician became stock figures in the cartoonists' visual repertoire. What other stock figures like Herblock's anthropomorphic "Mr. Atomic Bomb" have been added to the national cartoon repertoire? Are the communicative powers of contemporary cartoonists hampered by a visual vocabulary that is too often rooted in archaic imagery and forgotten historical allusions?

A second area of needed research concerns the political cartoon as an evolutionary record of social change. The cartoon is not only an artifact of the here and now but a valuable barometer of social and political change within a culture. For example, the Meyer and associates (1980) study of the evolving portrayal of women in July 4 th cartoons exemplifies research investigating a visual form to plot the changing image of a national subgroup, in this case the changing persona of the American woman.
Third, the influence of the sociopolitical climate in affecting the cartoon depiction of political events and persons is worthy of exploration. What impact does changing public opinion have on the ways the political cartoonists practice their craft? Goldman and Hagen (1978) demonstrated that the post-Watergate political climate influenced political cartoonists in their increasingly negative caricatures of Richard Nixon's facial physiognomy. Cartoonists during the 1980 presidential campaign were also influenced by the political attitudes of their mass readership. For example, Jimmy Carter's declining popularity and perceived lack of leadership resulted in his literally shrinking stature in many editorial cartoons: Carter was often drawn to half the scale of other candidates to visually portray his diminished political stature. Cartoonists in Campaign 1980 were also prevented from capitalizing on visual caricatures of Ronald Reagan's age because of growing national reluctance to tolerate "ageism," the ridicule of behaviors and traits associated with the elderly. ${ }^{8}$

Finally, there is the serious demand for experimental and field research on the ways in which newspaper readers use political cartoons. While this article has argued for four functions of political cartoonsentertainment, aggression reduction, agenda-setting, and framing - they by no means form an exhaustive list. Scholarly attention should be paid to the argument that the political cartoon is a fundamentally persuasive form of communication. Since Thomas Nast first lampooned the infamous Boss Tweed, there has been a historical association of the political cartoon with motivating social and political change. While the persuasive intention of cartoonists is well-documented, there has been little research into the effectiveness of the cartoon as visual rhetoric. ${ }^{9}$

Until these and other research topics are addressed, we are faced with a dilemma not unlike that of Lévi-Strauss's tribal chief: we are resolute in our belief that the often simple lines which create the editorial cartoon have meaning without fully understanding their real significance. 


\section{Notes}

See especially Kris (1952), chapters 6 and 7. Kris draws most of his ideas from Freud's work on the comic mind; see Sigmund Freud, Jokes and Their Relation to the Unconscious, tr. and ed. by James Strachey (New York: Norton, 1960). For a less extreme rendition of the psychoanalytic paradigm see E. H. Gombrich and Ernst Kris, Caricature (Harmondsworth: Penguin Books Ltd., 1940). For two explicitly political studies of caricature see D. B. Van Dalen, "Body Image and the Presidency: Abraham Lincoln," The Research Quarterly 46 (1975):489-497; Yeshayahu Nir, "U.S. Involvement in the Middle East Conflict in Soviet Caricatures," Journalism Quarterly 54 (1977):697-702. On biases against popular culture see C. W. E. Bigsby, "The Politics of Popular Culture," Cultures 1 (1973): 15-35.

For further analysis of the ramifications of a "cultural" versus "transmission" view of communication, see Carey (1975a:173-191 and 1975b:1-22).

Conclusions reported here are based on a study of 749 editorial cartoons; namely, all the editorial cartoons treating the 1980 presidential campaign from the Washington Post, the Los Angeles Times, the Chicago Tribune, and the Davis (Calif.) Enterprise from November 1, 1979, to November 1, 1980. The study included the work of 42 editorial cartoonists. (See Medhurst and DeSousa 1981.)

For studies which attempt to correlate artistic intention and reader interpretation, see LeRoy M. Carl, "Meaning Evoked in Population Groups by Editorial Cartoons" (Ph.D. diss., Syracuse University, 1967); see also Carl, "Political Cartoons: 'Ink Blots' of the Editorial Page," Journal of Popular Culture 4 (Summer 1970):39-45; ibid.: "Editorial Cartoons Fail to Reach Many Readers," Journalism Quarterly 45 (1968):533-535; Eunice Cooper and Marie Jahoda, "The Evasion of Propaganda: How Prejudiced People Respond to AntiPrejudice Propaganda," Journal of Psychology 23 (1947):15-25.

6 On classical and medieval theories of comedy see Alex Preminger, O. B. Hardison, Jr., and Kevin Kerrance, eds., Classical and Medieval Literary Criticism: Translations and Interpretations (New York: Frederick Ungar, 1974). Renaissance conceptions of comedy evidenced in the writings of Trissino, Cinthio, Sydney, Lope de Vega, and Mazzoni are found in Allan H. Gilbert, Literary Criticism: Plato to Dryden (Detroit: Wayne State University Press, 1962)

7 On agenda-setting in mass communication see Maxwell McCombs and D. L. Shaw, "The Agenda-Setting Function of the Mass Media," Public Opinion Quarterly 36 (1972):176-188; Marc Benton and P. Jean Frazier, "The Agenda-Setting Function of the Mass Media at Three Levels of 'Information Holding, " " Communication Research 3 (1976):261-274; Philip Palmgreen and Peter Clarke, "Agenda-Selting with Local and National Issues," Communication Research 4 (1977):435-452.

8 For a discussion of social forces influencing Carter and Reagan cartoon portrayals, see J. Adler et al. (1980:74-85).

9 See Carl's research cited in note 5; also see Del Brinkman, "Do Editorial Cartoons and Editorials Change Opinions?" Journalism Quarterly 45 (1968):724-726.

\section{References}

- Adler, J. et al.

1980 The Finer Art of Politics. Newsweek, October 13, 1980, pp. $74-85$.

- Alba, V

1966-1967 The Mexican Revolution and the Cartoon. Comparative Studies in Society and History 9:122-136.

Bogardus, E. S.

1945-1946 Sociology of the Cartoon. Sociology and Social Research 30:139-147.

Carey, J. W

1975a A Cultural Approach to Communication. Communication 2:122. 1975b Communication and Culture. Communication Research 2:173-191

- Coupe, W. A.

1966-1967 The German Cartoon and the Revolution of 1848. Comparative Studies in Society and History 9:137-167.

1969 Observations on a Theory of Political Caricature. Comparative Studies in Society and History 11:79-95.

- Dennis, E. E., and M. L. Dennis

1974100 Years of Political Cartooning. Journalism History 1:610.

- DeSousa, M. A

1981 Reflections in the Mirror: The 1980 Presidential Debates in Editorial Cartoons. Unpublished paper.

- Duncan, H. D.

1962 Communication and Social Order. New York: Oxford University Press.

- Geertz, C

1973 The Interpretation of Cultures. New York: Basic Books.

- Goldman, M., and M. Hagen

1978 The Forms of Caricature: Physiognomy and Political Bias. Studies in the Anthropology of Visual Communication 5:30 36.

- Gombrich, E. H.

1963 The Cartoonist's Armoury. In Meditations on a Hobby Horse. London: Phaidon.

- Graber, D. A

1980 Mass Media and American Politics. Washington, D.C.: Congressional Quarterly Press.

- Gruner, C. R.

1978 Understanding Laughter: The Workings of Wit and Humor. Chicago: Nelson Hall.

- Jaffe, A

1977 Symbolism in the Visual Arts. In Man and His Symbols. C.

Kris, E. Jung, ed. New York: Dell.

1952 Psychoanalytic Explorations in Art. New York: International Universities Press.

- Lévi-Strauss, C.

1977 Tristes Tropiques. J. and D. Weightman, trs. New York: Pocket Books.

- Mckeon, R., ed

1941 The Basic Works of Aristotle. New York: Random House.

- Meadow, R. G.

1980 Politics as Communication. Norwood, N.J.: Ablex.

- Medhurst, M. J., and M. A. DeSousa

1981 Political Cartoons as Rhetorical Form: A Taxonomy of Graphic Discourse. Communication Monographs 48:197-236.

- Meyer, K. et al.

1980 Women in Fourth of July Cartoons: A 100 Year Look. Journal of Communication 30:21-30.

- Morrison, M.

1969 The Role of the Political Cartoonist in Image Making. Central States Speech Journal 20:252-260.

- Noelle-Neumann, E.

1973 Return to the Concept of Powerful Mass Media. Studies of Broadcasting 3:67-112.

1974 The Spiral of Silence: A Theory of Public Opinion. Journal of Communication 24:43-51.

- Sproule, J. M.

1980 Argument: Language and Its Influence. New York: MCGraw-Hill.

- Streicher, L. H.

1965-1966 David Low and the Sociology of Caricature. Comparative Studies in Society and History 8:1-23.

1966-1967 On a Theory of Political Caricature. Comparative Studies in Society and History 9:427-445.

- Turner, K. J.

1977 Comic Strips: A Rhetorical Perspective. Central States Speech Journal 28:24-35. 